\title{
Examining Academic Writing Motivation of Prospective Indonesian Language Teachers Using Exploratory Factor Analysis
}

\section{Surastina}

Dr., corresponding author, Graduate School of Language Studies, STKIP PGRI Bandar Lampung, Bandar Lampung 35214, Indonesia, stkip.tina@gmail.com

\section{Fransisca S.O. Dedi}

Graduate School of Language Studies, STKIP PGRI Bandar Lampung, Bandar Lampung 35214, Indonesia

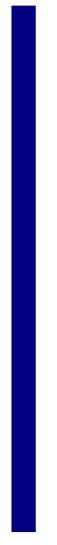

\begin{abstract}
Motivation determines students' success in academic writing. The current study adopted 28 items of the academic writing motivation questionnaire by Payne (2012) translated into Indonesian language to explore students' motivation in academic writing. This study involved 120 prospective Indonesian language teachers at STKIP PGRI Bandar Lampung that were chosen by stratified random sampling technique. The result indicated that items clustered into four factors, namely (1) enjoyment $\left(\alpha=0.98 ; \mathrm{s}^{2}=34.96 \%\right)$, (2) self-efficacy $\left(\alpha=0.91 ; \mathrm{s}^{2}=\right.$ $17.90 \%)$, (3) instrumentality $\left(\alpha=0.93 ; \mathrm{s}^{2}=14.44 \%\right)$, and (4) recognition $(\alpha=$ $0.98 ; \mathrm{s}^{2}=10.65 \%$ ) with rotated factor loadings varying between 0.546 and 0.984 . These results confirmed that the instrument used in this study had excellent validity and reliability. Based on degree of motivation analysis, the enjoyment had the highest contribution to writing motivation, followed by instrumentality, and selfefficacy. Finally, Pearson correlation analysis revealed the significant correlation between enjoyment and self-efficacy.
\end{abstract}

Keywords: academic writing motivation, prospective teacher, Indonesian language, exploratory factor analysis, Pearson correlation

\section{INTRODUCTION}

Writing is the most complex and important language skill because it permanently records information, opinions, beliefs, feelings, arguments, explanations, theories, and emotions (Erkan \& Saban, 2011). As a medium of communication, writing skills should be mastered by every learner to develop the thinking skills and patterns of grammar (Bangert-Drowns et al., 2004). It is impossible to achieve good academic performance without good writing skills (Hidi et al., 2004). Students who do not write well have

Citation: Surastina, \& Dedi, F. S. O. (2018). Examining Academic Writing Motivation of Prospective Indonesian Language Teachers Using Exploratory Factor Analysis. International Journal of Instruction, 11(2), 15-24. https://doi.org/10.12973/iji.2018.1122a 
difficulty in developing thinking skills (Hillocks, 2006), and at the later stage will not do well in the tertiary education and the workplace (Matsumura et al., 2015).

International assessment of students' writing performance has attracted public attention in the last decade. The 2011 research by National Center for Education Statistics, U.S. Department of Education, to 24.100 eighth-graders and 28,100 twelfth-graders reveals that $27 \%$ of students at both grades 8 and 12 performed at or above the proficient level which represents solid writing performance. They clearly demonstrated the ability to accomplish the communicative purpose of their writing. Meanwhile, $73 \%$ of them performed at or below the bbasic level that indicates partial mastery of the prerequisite knowledge and skills for academic writing (National Center for Education Statistics, 2012).

In the Indonesian case, some workers (lecturers, practitioners, business people) and college students perform the low writing skills and they are not used to write their ideas productively (Fahim \& Anshori, 2006; Nurhayati et al., 2015). Specifically, the research by World Bank (Gropello et al., 2011) compares skills most lacked with skills most needed among Indonesian younger and older workers. It found the writing skills as the most lacked skills for workers across generation. In line with that, the writing skills were also found as the skills less needed for olders than other skills such as computing, creativity, leadership, problem solving, etc. This report indicated that Indonesian workers had the lack of enthusiasm and motivation in writing. It seems to become a major cause of the low writing proficiency of Indonesian.

Motivation was known as an important factor that affects student performance in writing (Trola et al., 2012; Zimmerman \& Risemberg, 1997). Motivation itself consists of several components including self-efficacy, beliefs, attitudes, and goal orientation (Trola et al., 2012). A writer should develop their motivation and inner beliefs to become a good writer. Students who believe they are a competent writer show more effort in writing and demonstrate greater determination in seeking to write superbly well (Bottomley et al., 1997). Conversely, less motivation of students in writing is more likely to show excessive anxiety to readily engage in academic writing activities. Attempts to develop writing skills will not have a significant impact unless they foster the students' confidence (Brown et al., 2011). Consequently, it is necessary to conduct a research that focuses not only on improving technique but also on motivation and ultimately on self-motivation.

Our research addressed to explore academic writing motivation of prospective Indonesian language teachers by examining the degree of motivation and interrelationship between motivational factors. The Indonesian language is a compulsory subject from elementary to higher education in Indonesia. As a competency that must be mastered in Indonesian language curriculum (National Board of Education Standard, 2013), Indonesian students at every level of education should be trained and motivated as a good writer. Therefore, it is important to analyze the students' writing skills and motivation, including the prospective Indonesian language teachers. 


\section{METHOD}

\section{Sample}

The sample size used should be large enough to produce a reliable factor analysis (Costello \& Osborne, 2005; Field, 2009). The sample of this research was 120 prospective Indonesian language teachers who have been educated at 1 st-4th grade. The participants consisted of $38.33 \%$ male and $61.67 \%$ female that were chosen by stratified random sampling technique as shown in demographic information in Table 1.

Table 1

Summary of demographic information

\begin{tabular}{lcc}
\hline \multirow{2}{*}{ Background } & \multicolumn{2}{c}{ Subtotal } \\
\cline { 2 - 3 } & $\mathrm{n}$ & $\%$ \\
\hline Gender & 46 & 38.33 \\
Male & 74 & 61.67 \\
Female & 30 & 25 \\
\hline Grade & 30 & 25 \\
First (1) & 30 & 25 \\
Second (2) & 30 & 25 \\
Third (3) & & \\
Forth (4) & 120 & 100 \\
\hline Total & & \\
\hline
\end{tabular}

\section{Experimental design}

This research used survey method by distributing a questionnaire to prospective Indonesian language teachers who are studying in the first to fourth grade in the academic year 2016 - 2017 at STKIP Bandar Lampung, a private college of teacher training and education in Lampung Province, Indonesia. Survey method is well suited for use in research related to characteristics (abilities, preferences, behavior, etc.) of individuals, groups, or physical environments such as schools (Fraenkel et al., 2012). This method had been used by Rushidi (2012) to establish students' attitudes toward academic writing in a foreign language and Graham et al. (2007) to observe the structural relationship between achievement and attitudes.

The research was started with a review of literature, adaptation, and focus group discussions (FGD) to review the content of questionnaire. FGD was conducted by giving critiques and suggestions from two experts of the Indonesian language, and one expert of educational assessment. After making some changes based on expert suggestions, the questionnaires were distributed in February and March 2017. The collected data was analyzed through EFA to find meaningful patterns in this psychometric measures. In addition, the analysis of Cronbach $\alpha$ coefficient and Pearson product moment were also done to establish consistency and quantify the relationships between motivational factors.

\section{Instrument}

This study used the Academic Writing Motivation Questionnaire (AWMQ) adapted from Payne (2012). The original AWMQ consisted of 37 item statements in eight 
factors. After intensive FGD, we chose 29 items in four factors, discarding factors five to eight because they have a small percentage of variance and not fully represent the variables in AWMQ (Payne, 2012). Factor 1 (enjoyment) and factor 2 (self-efficacy) refer to students' intrinsic motivation and factor 3 (instrumentality) and factor 4 (recognition) refer to extrinsic motivation. Items on AWMQ were coded into five-pointLikert scales with ranges from 0 (strongly disagree) to 4 (strongly agree).

\section{Data analysis}

The AWMQ, developed in English and was translated into Indonesian language. The data obtained were analyzed in four stages. Firstly, we examined the pattern of the existence of factor structure using Exploratory Factor Analysis (EFA) including the Kaiser-Meyer-Olkin (KMO) measure of sampling adequacy and the Bartlett test of sphericity, the varimax rotational method, rotated factor loadings, and the percentage of variance (s2). Secondly, we calculated the Cronbach $\alpha$ coefficient to determine instrument reliability. Thirdly, we established the degree of academic writing motivation based on the mean value (M) and standard deviation (s) of each participant on each factor. Finally, we calculated the Pearson product moment to determine the relationship between factors.

\section{FINDINGS}

\section{Exploratory factor analysis}

Exploratory factor analysis (EFA) with varimax rotation method was applied to make it clear that the factors engage students in academic writing. The Kayser-Mayer-Olkin (KMO) value was 0.884 and Bartlett's chi-square $(\chi 2)$ approximation was 4566.96 with $\mathrm{p}=0.000$. A KMO value close to 1 indicated that the correlation pattern was compact enough to produce distinct and reliable factors. Additionally, the significance of the data on the Bartlett test will be achieved at $\mathrm{p}<0.001$. The KMO and Bartlett test scores indicated that the EFA method was appropriate to be used in this study and could be forwarded to eigenvalue analysis. Moreover, the other important question is whether the sample size used in this study was sufficient for factor analysis. Field (2009) revealed that the sample size for EFA depends on many things, but communalities after extraction should be above 0.50. Meeting these criteria, we find that almost every item had communalities after extraction of more than 0.50 . However, one item on Recognition factor had a low communalities value $(0.275)$, which indicates that this item cannot be included in the next analysis. The result deduces that the sample size was sufficient for factor analysis.

Finally, construct validation using orthogonal rotation with principal component analysis sorted the 28 items in the questionnaire into four factors as found by Payne (2012). Two factors were enjoyment and self-efficacy and called as intrinsic motivation, and the others were instrumentality and recognition and called as extrinsic motivation. The descriptions of these factors by Payne (2012) were as follows:

1. Enjoyment (12 items) measures participants' enjoyment to engage in writing activities, or their distaste for it. 
2. Self-efficacy ( 8 items) assesses participants' confidence in their writing ability.

3. Instrumentality ( 5 items) identifies participants' beliefs about writing as a means of achieving success.

4. Recognition (3 items) is primarily related to perceived rewards for writing, including feedback on writing.

Table 2

Factor loadings, Cronbach $\alpha$, and variance explained of each items of questionnaire

\begin{tabular}{|c|c|c|c|}
\hline \multicolumn{4}{|c|}{ Component } \\
\hline Factor 1: E & Factor 2: SE & Factor 3: I & Factor 4: R \\
\hline \multicolumn{4}{|c|}{ Factor 1: Enjoyment $(\mathrm{E}), \alpha=0.98, \mathrm{~s}^{2}=34.96 \%$} \\
\hline 0.903 & 0.306 & 0.065 & 0.046 \\
\hline 0.805 & 0.347 & -0.075 & -0.045 \\
\hline 0.855 & 0.267 & 0.035 & 0.095 \\
\hline 0.874 & 0.314 & 0.061 & 0.094 \\
\hline 0.869 & 0.273 & 0.010 & 0.002 \\
\hline 0.837 & 0.315 & 0.032 & -0.060 \\
\hline 0.881 & 0.287 & 0.024 & 0.077 \\
\hline 0.839 & 0.282 & 0.004 & 0.058 \\
\hline 0.904 & 0.200 & -0.003 & 0.064 \\
\hline 0.906 & 0.258 & 0.012 & 0.092 \\
\hline 0.771 & 0.321 & 0.143 & 0.032 \\
\hline 0.784 & 0.387 & 0.021 & -0.040 \\
\hline \multicolumn{4}{|c|}{ Factor 2: Self-Efficacy (SE), $\alpha=0.91, \mathrm{~s}^{2}=17.90 \%$} \\
\hline 0.334 & $\mathbf{0 . 7 2 0}$ & 0.034 & 0.133 \\
\hline 0.385 & 0.602 & -0.102 & 0.060 \\
\hline 0.408 & 0.697 & -0.046 & 0.067 \\
\hline 0.275 & 0.840 & 0.039 & -0.005 \\
\hline 0.416 & 0.598 & -0.078 & 0.004 \\
\hline 0.417 & 0.546 & -0.197 & 0.075 \\
\hline 0.315 & 0.717 & 0.130 & 0.031 \\
\hline 0.293 & 0.816 & 0.087 & -0.033 \\
\hline \multicolumn{4}{|c|}{ Factor 3: Instrumentality (I), $\alpha=0.93, \mathrm{~s}^{2}=14.44 \%$} \\
\hline 0.038 & -0.032 & 0.962 & -0.046 \\
\hline 0.031 & -0.039 & 0.949 & -0.033 \\
\hline-0.011 & 0.096 & 0.688 & 0.108 \\
\hline 0.059 & -0.056 & 0.964 & -0.019 \\
\hline 0.021 & 0.006 & 0.825 & 0.077 \\
\hline \multicolumn{4}{|c|}{ Factor 4: Recognition (R), $\alpha=0.98, \mathrm{~s}^{2}=10.65 \%$} \\
\hline 0.088 & 0.040 & 0.048 & 0.984 \\
\hline 0.033 & 0.060 & -0.033 & 0.979 \\
\hline 0.054 & 0.057 & 0.100 & 0.975 \\
\hline
\end{tabular}

\section{Degree of factors in academic writing motivations}

Suprapto (2016) showed that the mean and grand mean comparison of each participant in each factor reveals the attitude to STEM education (science, technology, engineering, and mathematics) among students. By this method, enjoyment (intrinsic motivation) was 
the most motivating factor in academic writing for students with $\mathrm{M}=3.45$ and $\mathrm{s}=0.50$, followed by instrumentality (extrinsic motivation) with $\mathrm{M}=3.09$ and $\mathrm{s}=0.60$, then selfefficacy (intrinsic motivation) with $\mathrm{M}=3.05$ and $\mathrm{s}=0.47$. These three factors showed greater value than the grand mean $(\mathrm{M}=3.02)$ which indicated that they do actually motivate students in writing activities.

Table 3

Degree of academic writing motivation

\begin{tabular}{llll}
\hline & $\mathrm{M}$ & $\mathrm{s}$ & Rank \\
\hline Enjoyment & 3.45 & 0.50 & $1^{*}$ \\
Self-Efficacy & 3.05 & 0.47 & $3^{*}$ \\
Instrumentality & 3.09 & 0.60 & $2 *$ \\
Recognition & 2.51 & 0.74 & 4 \\
Total & 3.02 & 0.36 & \\
\hline
\end{tabular}

\section{Interrelationship among factors in academic writing motivation}

In Table 4, we observed that the factor of enjoyment correlated significantly to selfefficacy with Pearson correlation coefficient was 0.718 . However, these two intrinsic factors did not correlate with the other two extrinsic factors. The two extrinsic factors, instrumentality and recognition, did not correlate with each other. These results confirmed that the items in the instrument had no meaningful bias and were able to distinguish two types of motivation clearly.

Table 4

Interrelationships among factors of academic writing motivation

\begin{tabular}{lllll}
\hline & 1 & 2 & 3 & 4 \\
\hline Enjoyment & 1 & & & \\
\hline Self-Efficacy & $0.718^{* *}$ & 1 & & \\
\hline Instrumentality & 0.057 & -0.008 & 1 & 1 \\
\hline Recognition & 0.113 & 0.123 & 0.060 & \\
\hline
\end{tabular}

** Correlation is significant at the 0.01 level (2-tailed).

\section{DISCUSSION}

The AWMQ instrument was used in this study to examine academic writing motivation of prospective Indonesian language teachers. The EFA analysis grouped 28 item statements into four factors with rotated factor loadings varying between 0.546 and 0.984. The loading factor meets to the EFA validation criteria by Stevens (2002) whereby the retained items must be greater than 0.40 to produce accurate information. EFA results in this study match with Payne's findings (2012) which also earned four main factors i.e.: enjoyment, self-efficacy, instrumentality, and recognition. Moreover, the instrument explained $75.58 \%$ of total variance with the greatest variance (almost triple that of other factors) found in enjoyment factor. It means that the motivation of students to write can be more explored from how much students enjoy their writing activities. The overall value of Cronbach $\alpha$ was 0.93 , indicating the high reliability of the items. These results confirmed that the instrument can be used in a further study to help researchers and/or teachers to understand academic writing motivation of students. 
The analysis on the degree of writing motivation showed that two intrinsic factor, enjoyment $(\mathrm{M}=3.45, \mathrm{~s}=0.50)$ and self-efficacy $(\mathrm{M}=3.05, \mathrm{~s}=0.47)$, and one extrinsic factor, instrumentality $(\mathrm{M}=3.09, \mathrm{~s}=0.60)$ had mean values greater than the grand mean $(\mathrm{M}=3.02, \mathrm{~s}=0.36)$. The result informs that among these components enjoyment factor showed a significant contribution in writing motivation. Pajares (2003) said that good intrinsic motivation (enjoyment and self-efficacy) provided a great impact on writing performance. It has been proved that students with good writing enjoyment and selfefficacy generally have better motivation in writing (Martinez et al., 2011; Prat-Sala \& Redford, 2012; Schunk, 2003).

In addition, according to the degree motivation analysis, this finding indicated that intrinsic factors play a more dominant role in controlling students' writing motivation than extrinsic factors. Students' tendencies on the intrinsic goals which may arise from students' awareness will have a better impact on writing performance than extrinsic goals. This result reinforced by Amabile (1985) which indicates that poetry written under extrinsic orientation shows less creativity than that with intrinsic orientation. Nevertheless, it is undeniable that the extrinsic factor (instrumentality) was the second most powerful component of students' writing motivation. Ryan and Deci (2000) argued that extrinsic motivation gives a significant contribution as a student enters adulthood. In this way, the instructor has to find a way extrinsically to motivate students so that they become intrinsically motivated (Ryan \& Deci, 2000).

An interesting point was also found from the mean values analysis for each item, where the range varying from 2.50 to 3.49 with the median value $\mathrm{M}=3.22$. The highest mean value was found for the statement "I enjoy writing assignments that challenge me" $(\mathrm{M}=$ 3.49). This response suggested that most prospective Indonesian language teachers consider that writing assignment is a challenging task and they are willing to strive to complete the task. Pajares \& Johnson (1996) revealed that greater interest and more effort in doing tasks, seeing the difficult tasks as a challenge, can only be performed by students with high self-efficacy. This could be an indication that the participants had a fairly good self-efficacy as confirmed in the previous analysis. However, the item of recognition "I like to get feedback from an instructor on my writing" $(M=2.50)$ had the lowest mean score. We speculate that many participants prefer free writing for themselves without the need for feedback from the instructors. They do not want to accept any correction about their writing.

Pearson product moment analysis found that only intrinsic components showed the significant correlation. This finding also supported by Martinez et al. (2011) that enjoyment of leisure writing had a significant and positive correlation with self-efficacy. It means that students engaged in writing activities because it is inherently interesting or enjoyable can trigger writing self-efficacy, and vice versa. Additionally, these results revealed that the instrument had a high degree of differentiation and was able to distinguish sharply between intrinsic and extrinsic items. The relationship of these four factors in academic writing motivation can be illustrated in Figure 1. 


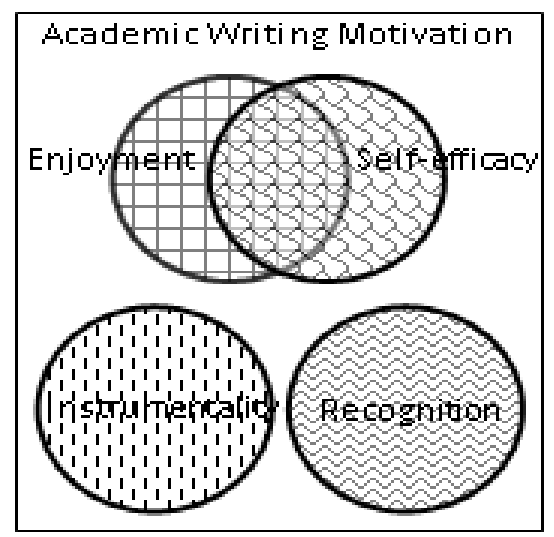

Figure 1

Representation of the relationships between motivations in academic writing

\section{CONCLUSION}

This study reported that the instrument was suitable for further assessment of students' academic writing motivation with high construct validity and reliability of the items. Motivation covered in this instrument was intrinsic motivation (enjoyment and selfefficacy) and extrinsic motivation (instrumentality and recognition). Based on EFA results, students' writing motivation can be more explained by enjoyment factor which had the greatest variance $\left(\mathrm{s}^{2}=34.96 \%\right)$. Moreover, degree of motivation analysis revealed that enjoyment $(\mathrm{M}=3.45, \mathrm{~s}=0.50)$ came to the first rank in writing motivation, followed by instrumentality $(\mathrm{M}=3.09 ; \mathrm{s}=0.60)$, and self-efficacy $(\mathrm{M}=$ $3.05 ; \mathrm{s}=0.47)$. The result found that only the enjoyment and self-efficacy were correlated significantly.

\section{REFERENCES}

Amabile, T. M. (1985). Motivation and Creativity: Effects of motivational orientation on creative writers. Journal of Personality and Social Psychology, 48(2), 393-399.

Bangert-Drowns, R. L., Hurley, M. M., \& Wilkinson, B. (2004). The effects of schoolbased writing-to-learn interventions on academic achievement: A meta-analysis. Review of Educational Research, 74(1), 29-58.

Bottomley, D. M., Henk, W. A., \& Melnick, S. A. (1997). Assessing children's views about themselves as writers using the writer self-perception scale. The Reading Teacher, 51(4), 286-296.

Brown, K. W., West, A. M., Loverich, T. M., \& Biegel, G. M. (2011). Assessing adolescent mindfulness: Validation of an adapted mindfulness attention awareness scale in adolescent normative and psychiatric populations. Psychological Assessment, 23(4), 1023-1033. 
Costello, A. B., \& Osborne, J. W. (2005). Best practices in exploratory factor analysis: Four recommendations for getting the most from your analysis. Practical Assessment, Research \& Evaluation, 10(7), 1-9.

Erkan, D. Y., \& Saban, A. I. (2011). Writing performance relative to writing apprehension, self-efficacy in writing, and attitudes towards writing: A correlational study in turkish tertiary-level EFL. Asian EFL Journal, 3(1), 163-191.

Fahim, M. \& Ansari, D. N. (2006). A multiple intelligence-based investigation into the effects of feedback conditions on EFL writing achievement. Indonesian Journal of Applied Linguistics, 9(2), 51-78.

Field, A. P. (2009). Discovering statistics using SPSS. 2nd Ed. London: Sage Publication.

Fraenkel, J. R., Wallen, N. E. \& Hyun, H. H. (2012). How to design and evaluate research in education. 8th Ed. New York: McGraw-Hill.

Graham, S., Berninger, V., Fan, W. (2007). The structural relationship between writing attitude and writing achievement in first and third grade students. Contemporary Educational Psychology, 32(3), 516-536.

Gropello, E., Kruse, A., Tandon, P. (2011). Skills for the labor market in Indonesia: Trends in demand, gaps, and supply. Washington, D. C.: World Bank.

Hidi, S., Renninger, K. A., Krapp, A. (2004). Interest, a motivational variable that combines affective and cognitive functioning. In Motivation, emotion, and cognition: Integrative perspectives on intellectual functioning and development (pp: 89-115). New Jersey: Lawrence Erlbaum Associates, Inc.

Hillocks, G. (2006). Middle and high school composition. In Research on composition: Multiple perspectives on two decades of change (pp. 48-77). New York: Teachers College Press.

Martinez, C. T., Kock, N., \& Cass, J. (2011). Pain and pleasure in short essay writing: factors predicting university students' writing anxiety and writing self-efficacy. Journal of Adolescent \& Adult Literacy, 54(5), 351-360.

Matsumura, L. C., Correnti, R., Wang, E. (2015). Classroom writing tasks and student's analytic text-based writing. Reading Research Quarterly, 50/4, 417-438.

National Board of Education Standard. (2013). The regulations of minister of education and culture (Attachment No. 21, 2016). Retrieved from http://bsnpindonesia.org/?page_id=103.

National Center for Education Statistics. (2012). The nation's report card: writing 2011. Washington DC, Institute of Education Sciences, U.S. Department of Education.

Nurhayati, I. K., Noviaristanti, S., \& Priyanto, T. (2015). Indonesian employees' writing skills, linguistic intelligence, and critical thinking levels. Proceeding of Enhancing Organizational Survivability Through Learning Organization: 3rd International Seminar 
and Conference on Learning Organization (pp. 1-6), Yogyakarta, Indonesia: Atlantis Press.

Pajares, F., \& Johnson, M. J. (1996). Self-efficacy beliefs and the writing performance of entering high school students. Psychology in the Schools, 33(2), 163-175.

Pajares, F. (2003). Self-efficacy beliefs, motivation, and achievement in writing: a review of the literature. Reading \& Writing Quarterly: Overcoming Learning Difficulties, 19(2), 139-158.

Payne, A. R. (2012). Development of the academic writing motivation questionnaire. Master's thesis. University of Georgia, Georgia, USA.

Prat-Sala, M., \& Redford, P. (2012). Writing essays: Does self-efficacy matter? The relationship between self-efficacy in reading and in writing and undergraduate students' performance in essay writing. Educational Psychology, 32(1), 9-20.

Rushidi, J. (2012). Perceptions and performance: Students'attitudes towards academic english writing. SEEU Review, 8(2), 1-15.

Ryan, R.M., \& Deci, E.L. (2000). Intrinsic and extrinsic motivations: Classic definitions and new directions. Contemporary Educational Psychology, 25(1), 54-67.

Schunk, D. H. (2003). Self-efficacy for reading and writing: Influence of modelling, goal setting, and self-evaluation. Reading \& Writing Quarterly, 19(2), 159-172.

Stevens, J. (2002). Applied multivariate statistics for the social sciences. Mahwah, NJ: Erlbaum.

Suprapto, N. (2016). Students' attitudes towards STEM education: Voices from indonesian junior high schools. Journal of Turkish Science Education, 13(3), 75-87.

Trola, G. A., Shankland R. K., Harbaugh A. G., Wolbers K. (2013). Relationships between writing motivation, writing activity, and writing performance : effect of grade, sex and ability. Reading and Writing, 26(1), 17-44.

Zimmerman, B. J., \& Risemberg, R. (1997). Caveats and recommendations about selfregulation of writing: A social cognitive rejoinder. Contemporary Educational Psychology, 22(1), 115-122. 